\title{
Design of intelligent load frequency control strategy using optimal fuzzy-PID controller
}

\section{Nour El Yakine Kouba*, Mohamed Menaa, Mourad Hasni and Mohamed Boudour}

Laboratory of electrical and industrial systems (LSEI), University of Sciences and Technology Houari Boumediene, USTHB, BP 32 El Alia, 16111,

Bab Ezzouar, Algiers, Algeria

Email:nkouba@usthb.dz

Email:mmenaa@usthb.dz

Email:mhasni@usthb.dz

Email: mboudour@usthb.dz

*Corresponding author

\begin{abstract}
This paper proposes a robust control strategy involving a novel optimised fuzzy-PID controller tuning by particle swarm optimisation (PSO) algorithm. The proposed control strategy was suggested to design an intelligent load frequency control (LFC) scheme in multi-area interconnected power system. The PSO algorithm was employed to optimise the fuzzy-PID controller parameters including the scaling factors of fuzzy logic and the PID controller gains for minimisation of both system frequency deviation and tie-line power changes during load disturbances using the integral time multiply absolute error (ITAE) as objective function. To demonstrate the effectiveness of the proposed control strategy, the three-area 9-unit interconnected power system was used for the simulation. The superiority of the proposed approach was shown by comparing the obtained results to other strategies available in literature. Initially, the simulation was performed using the same controllers in each area, and then was extended with different controllers in each area. The comparative study demonstrates the potential of the proposed control strategy and shows its robustness to enhance frequency stability.
\end{abstract}

Keywords: load frequency control; LFC; multi-area control; PID controller; optimal control; particle swarm optimisation; PSO; fuzzy logic controller; FLC.

Reference to this paper should be made as follows: Kouba, N.E.Y., Menaa, M., Hasni, M. and Boudour, M. (2016) 'Design of intelligent load frequency control strategy using optimal fuzzy-PID controller', Int. J. Process Systems Engineering, Vol. 4, No. 1, pp.41-64.

Biographical notes: Nour El Yakine Kouba received his Masters degree in Electrical Engineering in 2012 from Faculty of Electrical Engineering and Computing; University of Sciences and Technology Houari Boumediene of Algiers. He is currently working toward his $\mathrm{PhD}$ at the Laboratory of Electrical and Industrial Systems (LSEI), University of Sciences and Technology Houari Boumediene of Algiers, Algeria. He is a member of the Association of Science and Electrical Technologies (ASTE). His interests include power system stability and control, automatic generation control (AGC), PID controller, optimisation techniques, metaheuristic and swarm intelligence, battery and wind power generation. 
Mohamed Menaa received his Ing and MS degrees in Electrical Engineering from Houari Boumediene University of Sciences and Technology 'USTHB', and received his $\mathrm{PhD}$ from Algiers Polytechnic School, Algiers, Algeria in 2007. Currently, he is an Associate Professor of Electrical Power Engineering at the Electrical Engineering Department, USTHB. His research interests include modelling and control of electric systems, identification and sensorless control, renewable energy, spiral vector theory.

Mourad Hasni received his Engineer, Master and Doctorate degrees in Electrical Engineering in 1991, 1996 and 2007 respectively from National Polytechnic School of Algiers. Currently, he is a Professor in Electrical Engineering Department at Houari Boumediene University of Sciences and Technology (USTHB, Algiers, Algeria). His research interests are in modelling, parameter estimation, fault detection of electrical machines and power systems.

Mohamed Boudour received his BSc, MSc and PhD in Electrical Engineering from the Polytechnic School of Algiers in 1991, 1994 and 2004, respectively. Since January 1994, he has been with the University of Sciences and Technology Houari Boumediene of Algiers (USTHB) as a teacher and researcher. He was awarded as a Fulbright Fellowship in the University of Washington, Seattle (USA) from 2005-2006. He is a member of the executive committee of ARELEC (Algerian CIGRE) and IEEE Senior Member since 2007. His main interests are power systems stability and control using intelligent programming, integration of renewable energy sources in smart grids. He is currently the President of the IEEE PES Chapter-Algeria and the Director of Electrical and Industrial System Laboratory.

This paper is a revised and expanded version of a paper entitled 'Load frequency control in multi-area power system based on fuzzy logic-PID controller' presented at IEEE International conference on Smart Energy Grid Engineering (SEGE), Oshawa, Canada, 17-19 August 2015.

\section{Introduction}

Modern electrical networks are the most complicated systems created by human. Hence, increasing size of the interconnected power systems has been accompanied with a series of challenging issues concerning the stability and control of overall system, which may result in disconnection actions, loss of several lines, zone isolation and deregulation of electricity markets (Kouba et al., 2015d). In such situations, any failure in planning, protection, operation and ancillary control actions of any part of the entire electrical network could evolve into the case of cascading events that may eventually lead to a large area power blackout. Thus, these challenging issues set novel demands on the development of more robust and rapid control strategies. Nowadays, numerous complex problems have to be solved by the power system engineers and researchers to ensure electric power with good quality (Kouba et al., 2015c; Kerdphol et al., 2015; Nageswara and Reddy, 2011). The frequency instability problem is one of among others problems which are concerned with security and reliability of power system operation and control. The frequency instability can be defined as the inability of a power system to keep system frequency within the specified operating limits. However, the frequency 
instability is a result of a significant imbalance between supply and load, and it is associated with poor coordination of control and protection equipment, insufficient generation reserves and inadequacies in equipment responses (Modi et al., 2013).

From this perspective, the feasibility of automatic generation control (AGC) becomes apparent. The main task of the AGC system is to keep the system frequency at nominal value and preserving power transfer between the controlled areas by changing output of selected units (Rahmani and Sadati, 2013). As an important function of AGC, power system frequency regulation named load frequency control (LFC) is considered as a vital ancillary service in power system. Therefore, the interest in LFC is growing up rapidly due to the interest in large interconnected power systems (Panda and Kumar Yegireddy, 2013). In a wide-area interconnected power system with two or more independently controlled areas, the foremost task of the secondary LFC loop is to control the generation among these areas and hold the frequency close to the required nominal value against the randomly varying active power loads, and minimise the tie-line power exchange error (Shirvani et al., 2012). Therefore, a control error signal, called the area control error (ACE) is measured, which represents the real power imbalance between generation and load. ACE signal is a linear combination of net interchange and frequency deviations (Wu and Yang, 2013).

In recently years, many works and papers have proposed different control methods and strategies to improve the AGC performance. In contrast, the difficulties in AGC are not only to design a robust LFC controller but it also to optimise its parameters effectively for optimal solution. Optimal active power and frequency control is one example of an optimisation problem which is concerned with security and reliability of power system. Over the past decades several control strategies and intelligent approaches have been proposed by many researchers for optimal AGC of power system. To improve the AGC system, many optimisation techniques, meta-heuristic methods and control configurations such as conventional (Ziegler and Nichols, 1942; Astrom and Hagglund, 2001), genetic algorithm (GA) (Shankar et al., 2012; Chavda and Prabhakaran 2015), particle swarm optimisation (PSO) (Kouba et al., 2014c), bacterial foraging optimisation algorithm (BFOA) (Salim Ali and Abd-Elazim, 2010), firefly algorithm (FA) (Chandra Saikia and Kant Sahu, 2013), artificial bee colony (ABC) (Kouba et al., 2015f), gravitational search algorithm (GSA) (Kouba et al., 2015b), bat algorithm (BA) (Kouba et al., 2015a), and fuzzy logic and multi-stage fuzzy (Yousef et al., 2014). Several others hybrid methods such as the hybrid bacterial foraging and particle swarm optimisation (BF-PSO) (Kouba et al., 2014b; Panda et al., 2013b) are also used by some researchers.

Over the past years, new optimal and robust control strategies have been applied to regulate many industrial systems that require robustness against various possible disturbances, where the PID controller and fuzzy logic control are the most used regulators in large published papers. In 2011, Panda and Tade have published a modified smith predictor with PID structure for control of multivariable processes. In 2012, Volosencu has proposed a tuning fuzzy PID controllers. An optimal fuzzy control of nonlinear systems has been also suggested in Krokavec and Filasova (2012). Recently, Zamani et al. (2014) have proposed an optimal fuzzy LFC with simultaneous auto-tuned membership functions and fuzzy control rules.

In view of the above, we propose to use in the present paper a new control strategy which involves PSO algorithm to tune the input and output scaling factors of fuzzy-PID controller for the LFC loop of an interconnected power system. The performance of the proposed control strategy was investigated for three-area interconnected power systems. 
The superiority of the proposed approach is shown by comparing the results with recently published modern heuristic optimisation approaches for the same interconnected power system. From the results it is can be observed that the proposed controllers are robust and need not be retuned when the system is subjected to various disturbances. From the obtained results, the capability of the proposed control strategy to enhance frequency stability was confirmed.

This paper is organised as follows. Section 2 describes the frequency regulation problem. Section 3 presents the suggested control strategy. Section 4 discusses the simulation results. Finally, Section 5 concludes the paper.

\section{Problem formulation}

Presently most of power systems are interconnected with their neighbouring areas and the frequency control problem becomes a joint big challenge. The modelling of a typical interconnected multi-area power system is presented in this section (Kouba et al., 2015d).

\subsection{System under study}

The three-area 9-unit model system shown in Figure 1 was used as test system. This system consists of three control areas, and each area has three parallel-operating generating units that are owned by different generation companies (Gencos). Every generating unit has a non-reheat turbine unit (Kouba et al., 2014a). It is assumed that the LFC signals are inputted to the governors of each unit to regulate the valve position.

Figure 1 Three-area 9-unit interconnected power system model

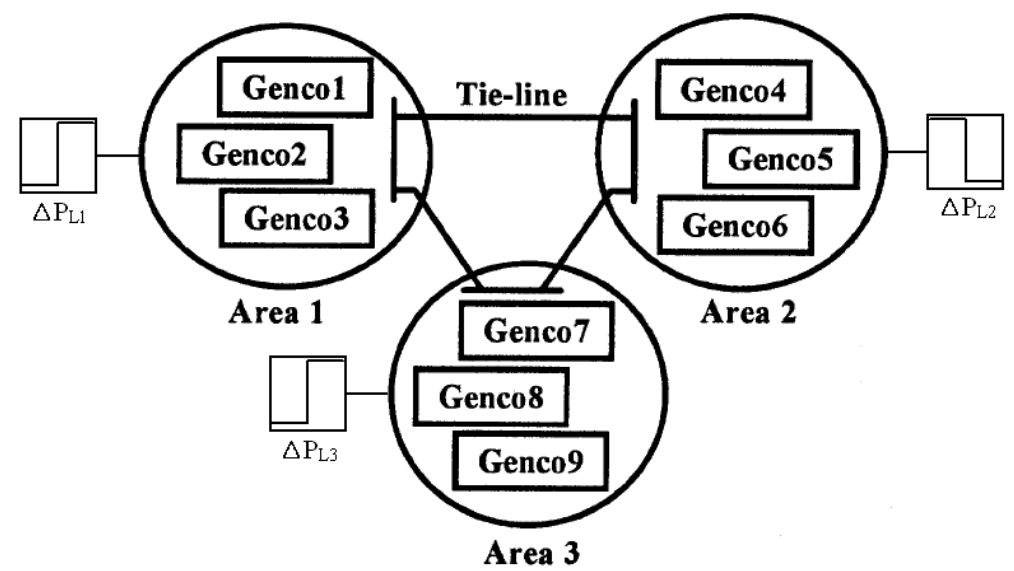

Normally a large interconnected electrical network is made up of several control areas tied with each other by tie-lines power flow. In each area, a load frequency controller (LFC) observes and monitors the system frequency and the tie-line power flows between interconnected zones. Each area is represented with three major components: generator, turbine, and governor control system as shown in Figure 2. 
Figure 2 LFC control loop of a synchronous generator (see online version for colours)

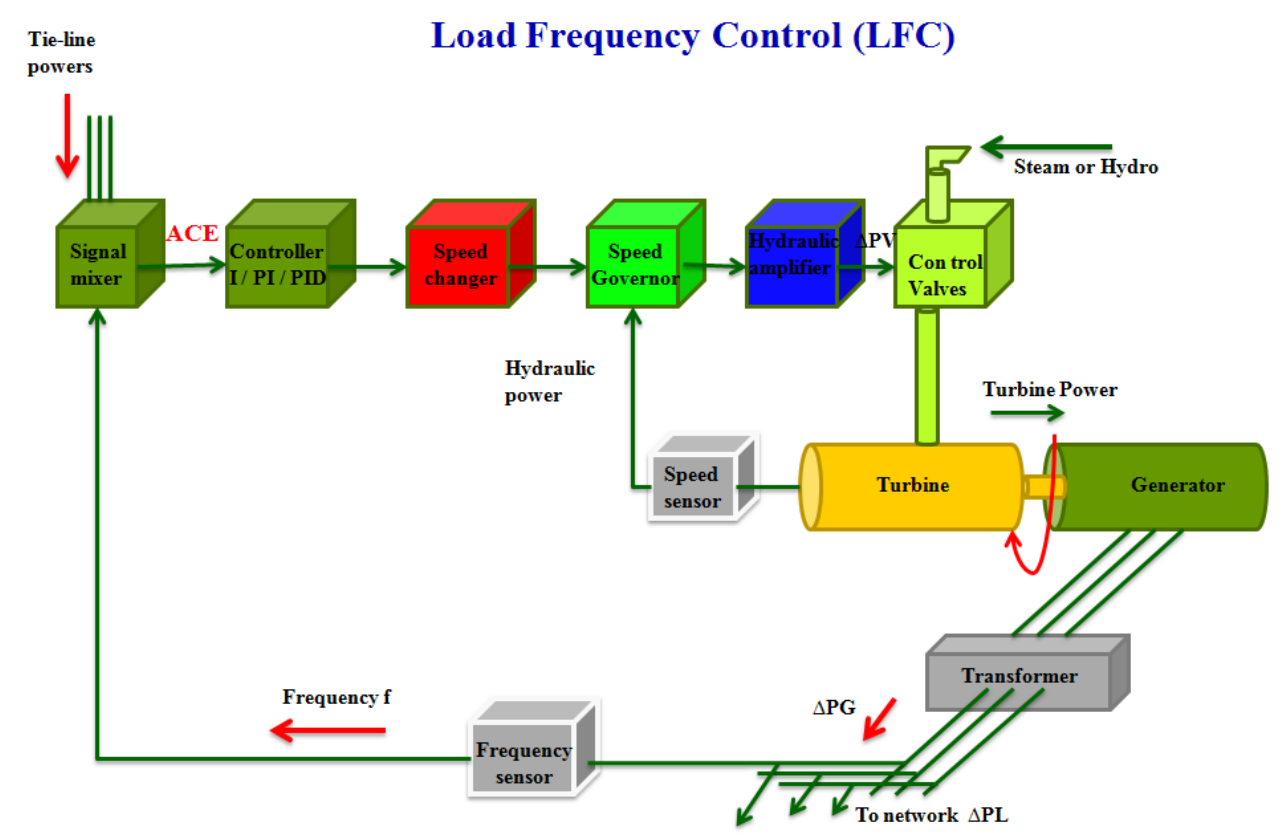

In this interconnected electrical network, each region is connected to the other through a tie-line. In order to control the system frequency, the LFC loop was equipped with a fuzzy-PID controller in each control zone. The dynamic model of a generic control area $i$ including $n$ generators is shown in Figure 3 (Rerkpreedapong et al., 2003).

Figure 3 Dynamic model representation of control area $i^{\text {th }}$

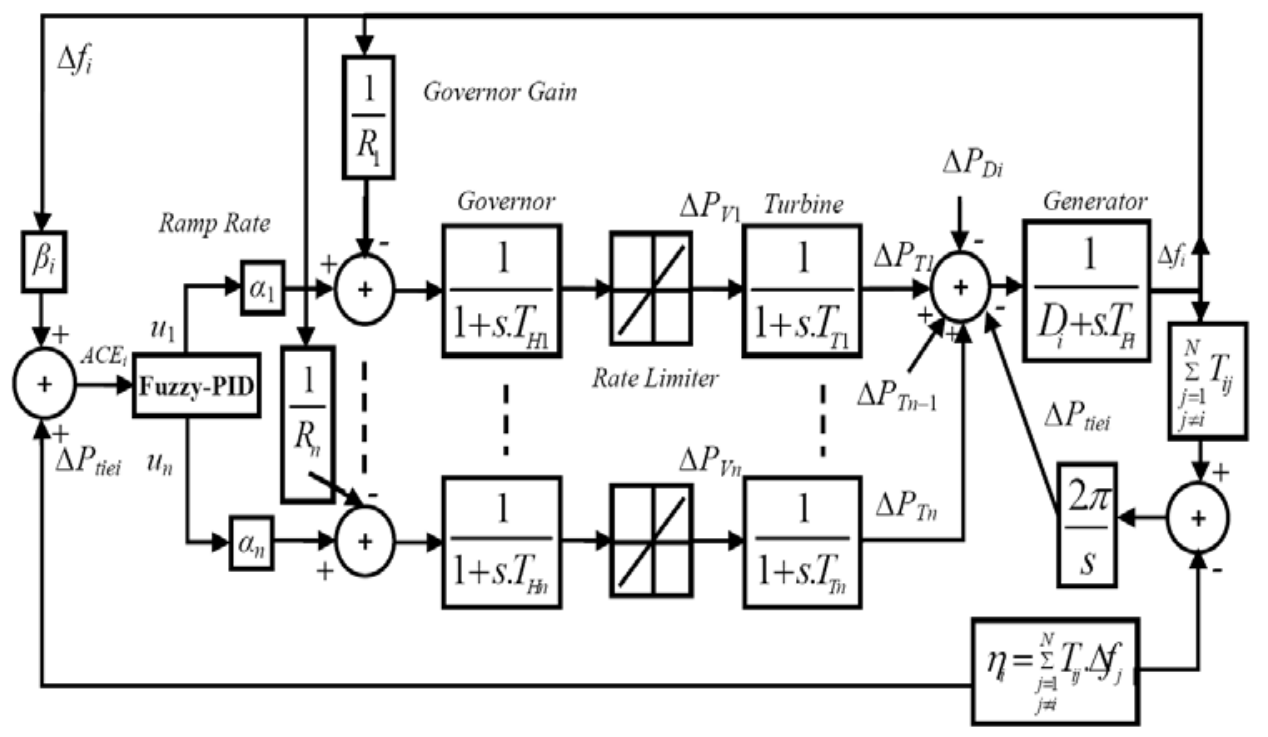




\subsubsection{Generator model}

The generator is a system which converts mechanical power provided by the turbine to electrical power. The relationship between the mechanical power and the electrical power is represented by the swing equation of a synchronous machine to small perturbation (Bevrani, 2009):

$$
T_{P} \frac{d \Delta f}{d t}=\Delta P_{m}-\Delta P_{e}
$$

Power system loads are a composite of a variety of electrical devices. Some loads depend on the change of frequency and others don't. In general the expression of the electrical power which depends on the change on the frequency can be expressed by (Bevrani, 2009; Wood and Wollenberg, 1966):

$$
\Delta P_{e}=\Delta P_{D}+D \Delta w
$$

where $\Delta w$ is rotor speed deviation, $M$ is inertia constant, $\Delta P_{D}$ is non-frequency-sensitive load change, $D$ is load-damping constant and $D . \Delta w$ is Frequency-sensitive load change.

In multi-machines system, if there are several power generating units operating in parallel in the same region, and if all generators are assumed turn with the same speed of synchronism, an equivalent generator will be developed to represent all the area for simplicity. The equivalent generator inertia constant, and the equivalent load-damping constant can be represented as follows:

$$
\begin{gathered}
T_{P e q}=\sum_{i=1}^{i=n} T_{P i} \\
D_{e q}=\sum_{i=1}^{i=n} D_{i}
\end{gathered}
$$

The equivalent generator equation is given by:

$$
\frac{d \Delta f_{i}}{d t}=\frac{1}{T_{P e q_{i}}}\left(\sum_{l=1}^{l=n} \Delta P_{T_{l i}}-\sum \Delta \text { Ptie }_{i}-\Delta P_{D_{i}}-D_{e q i} * \Delta f_{i}\right)
$$

\subsubsection{Governor-turbine model}

The governor represents a valve that controls the amount of fuel or steam running into the system. In other hand, a mechanical system named Turbine, which converts thermal power provided by the governor to mechanical power. To bring the frequency back to the nominal value and maintain the constancy of the rotor speed, each generator with governor adjusts the turbine valve/gate (self control) (Wood and Wollenberg, 1966). The mathematical formulations of this model are given by:

$$
\frac{d \Delta P v}{d t}=\frac{1}{T_{H}}(u-(K G * \Delta f)-\Delta P v)
$$




$$
\frac{d \Delta P_{T}}{d t}=\frac{1}{T_{T}}\left(\Delta P v-\Delta P_{T}\right)
$$

\subsubsection{Tie-line model}

In an interconnected multi-area power system, different areas are tied with each other by tie-lines, and the power flows between the areas are allowed by these tie-lines. Using DC load flow method, and assumed that the tie-line power flow is going from area- $i$ to area- $j$ as shown in Figure 4. The deviation $\Delta P_{T i j}$ from the nominal flow can be expressed (Kundur, 1994):

$$
\Delta P_{T i j}=\frac{T}{S}\left(\Delta f_{i}-\Delta f_{j}\right)
$$

Figure 4 Block diagram of the tie-line model

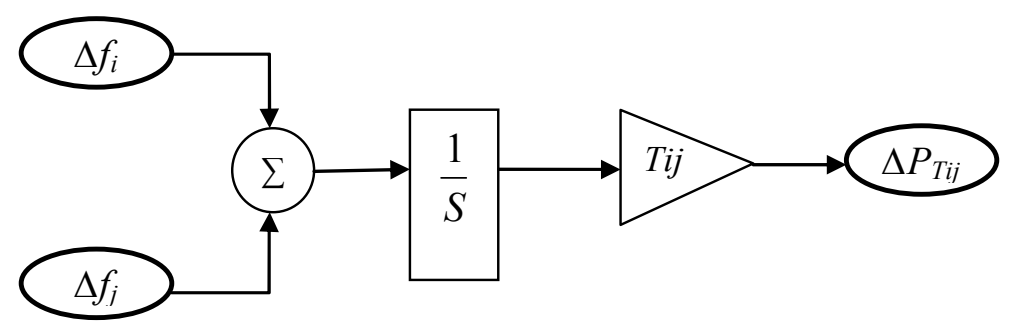

Figure 5 Frequency control levels (see online version for colours)

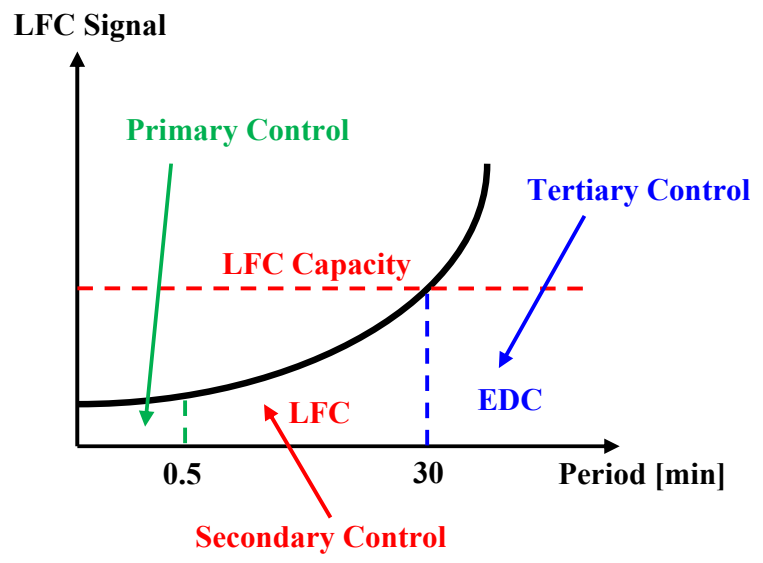

\subsection{LFC model}

In large-scale power systems, the total generation should meet the total demand and transmission loss. However, the main problem in the parallel operation of such interconnected power systems is the control of active power and frequency deviations. To maintain the system frequency to the nominal value, the mismatch between the generation and load must be at zero. Hence, to ensure the quality of power supply, power 
system was supported by many ancillary services termed as AGC. The main task of AGC is to minimise the system deviations and ensure a good management of power system in case of any perturbation. Regarding frequency regulation, the AGC system has three vital control levels as shown in Figure 5. Where, each control system was employed to hold the frequency at the specified values (Murty, 2008; Wang and McCalley, 2013).

Primary control: is a manual control implemented through the governor-turbine control system, which is installed in each generating unit and he starts within seconds of a disturbance. The focus of this control is to stabilise the frequency system but not return the frequency to its nominal value (Murty, 2008). On the other hand, the secondary control named LFC plays an important role in power system restoration by maintaining scheduled system frequency and tie-line power changes during load perturbations.

In addition, the tertiary control which refers to the economic dispatching control (EDC) of units presents a part of the regular market clearing mechanism and acts on minute-to-hours time scale (ten minutes- hours) (Wang and McCalley, 2013).

To achieve a good power quality with a stable operation condition, power system need to be restored to a normal working range as rapidly as possible within few seconds. In this aim, the actual frequency and net interchange power flow between controlled areas are measured by the independent system operator (ISO). $A C E$ is a measure of a balancing area's generation error. This latter can be written as follow (Murty, 2008; Wang and McCalley, 2013; Kirby et al., 2001):

$$
A C E_{i}=\Delta P_{T i j}+\beta_{i} \Delta w_{i}
$$

where $\beta_{i}$ is the frequency response characteristic for area $i$.

In the case of multi-generator we can calculate the equivalent frequency bias factor by:

$$
\beta e q=\sum_{i=1}^{i=n} \frac{1}{R_{i}}+\sum_{i=1}^{i=n} D_{i}
$$

In the case of interconnected multi-area power system, the state space model is given in equation (11) (Kouba et al., 2014a):

$$
\left\{\begin{array}{l}
\dot{X}=A X+B U \\
Y=C X
\end{array}\right.
$$

where

$$
\left\{\begin{array}{l}
U=\left[\begin{array}{ll}
\Delta P_{D 1} \cdots \Delta P_{D i} & u_{1} \cdots u_{i}
\end{array}\right]^{t} \\
Y=\left[\begin{array}{ll}
Y_{1} & Y_{2}
\end{array}\right]^{t}=\left[\begin{array}{ll}
\Delta f_{1} \cdots \Delta f_{i} & \Delta P_{t i e_{2}} \cdots \Delta P_{t i i_{i j}}
\end{array}\right]^{t} \\
X=\left[\begin{array}{ll}
X_{D_{1}} \cdots X_{D i} & X_{Z i}
\end{array}\right]^{t}, X_{Z_{i}}=\left[\begin{array}{ll}
\Delta f_{i} & \Delta P_{t i e_{i j}}
\end{array}\right] X_{D 1}=\left[\begin{array}{ll}
\Delta P_{T 1} & \Delta P_{V 1}
\end{array}\right], \\
X_{D_{i}}=\left[\begin{array}{ll}
\Delta P_{T_{n}} & \Delta P_{V n}
\end{array}\right]
\end{array}\right.
$$

The matrices $A, B$ and $C$ in (11) are given in the Appendix. 


\section{Proposed intelligent LFC scheme}

LFC restoration loop of inter-area power system presents a key issue on frequency regulation and network stability concerning load disturbances. In the most industrial systems, the LFC loop is compensated by a PI or PID controller. While, with the increasing size of the interconnected power systems, a sophisticated frequency control strategy is needed to satisfy a stable and good power quality. Hence, to face different disturbances in the modern power system, the design of an intelligent LFC controller for industrial systems has been often referred as an effective solution for enhancing frequency system. In this paper, a fuzzy-PID controller tuning by a meta-heuristic optimisation technique named PSO was employed to design an intelligent LFC loop as shown in Figure 6, where the design objective is to restore system frequency at nominal value as fast as possible within few seconds.

Figure 6 Proposed scheme for the optimised fuzzy-PID controller

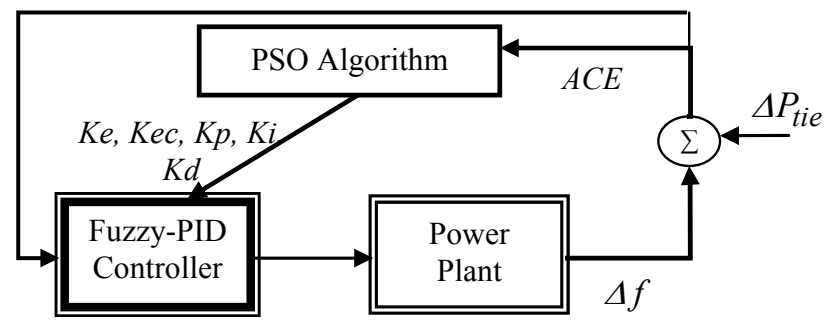

\subsection{Fuzzy logic controller}

The fuzzy logic theory was developed at the University of California, in Berkeley by the Iranian Professor, Dr. Lotfi Zadeh in 1965 when he wrote his first paper entitled fuzzy sets (Kouba et al., 2015d; Bevrani and Daneshmand, 2012b). Because of simplicity, robustness, and reliability, fuzzy logic is used in almost all industrial automation and process control fields (Kouba et al., 2015d). This logic is the mathematical representation of the formation of human concepts and of reasoning concerning human concepts. Fuzzy logic is a simple rule on the basis of: If $a$ and $b$ then $c$ and this logic represent something between 0 and 1 (Natsheh and Buragga, 2010; Mallesham and Rajani, 2006). Fuzzy controller is composed of the following blocks: fuzzification block, inference mechanism, knowledge base and defuzzification block (Zadeh, 1965; Daliri et al., 2011; Verma et al., 2013; Tang et al., 2000; Ram and Jha, 2010).

In this part, the structure of the fuzzy-PID controller is designed as shown in Figure 7, where the optimised structure is presented in the next part. Focusing basically on frequency stability, a parallel combination between fuzzy logic controller and PID controller was adopted in this work. The error inputs to the controllers are the respective $A C E$ given by:

$$
\begin{aligned}
& e_{1}=A C E_{1}=\Delta P_{t i e 12}+\Delta P_{t i e 13}+\beta_{1} \Delta f_{1} \\
& e_{2}=A C E_{2}=\Delta P_{t i e 12}+\Delta P_{t i e 23}+\beta_{2} \Delta f_{2} \\
& e_{3}=A C E 3=\Delta P_{t i e 31}+\Delta P_{t i e 32}+\beta_{3} \Delta f_{3}
\end{aligned}
$$


The proposed optimal fuzzy-PID controller-based PSO uses errors and derivative of errors $\left(e_{1}, e_{2}, e_{3}\right)$ as input signals. The outputs of the controller's $u 1, u 2$ and $u 3$ are the control inputs for each control area.

Figure 7 Structure of fuzzy-PID controller

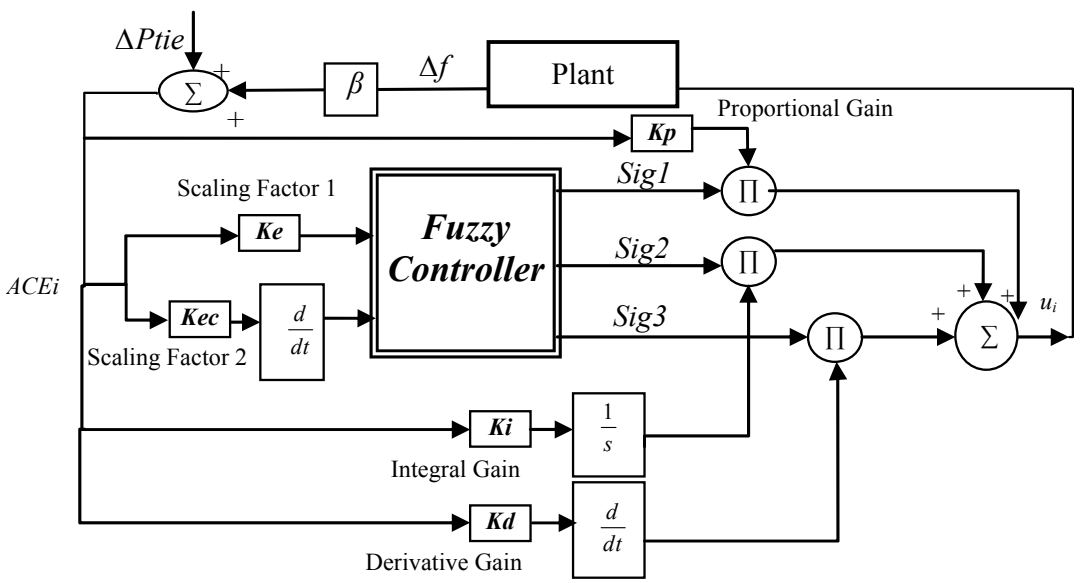

The input scaling factors are the tunable parameters $K_{e}$ and $K_{e c}$. The proportional, integral and derivation gains of PID controller are represented by $K p, K i$, and $K d$ respectively.

The inputs of the fuzzy logic control are the variables error $(A C E)$ and change of error $(d A C E)$, and in the outputs of fuzzy logic the control signals are calculated out according to offline rules in fuzzy controller as shown in Figure 8.

A label set corresponding to linguistic variables of the input control signals, $A C E(k)$ and $d A C E(k)$, with a sampling time of $0.01 \mathrm{sec}$ is as follows:

$$
\operatorname{Li}(A C E, d A C E)=\{N B \quad N S \quad Z E \quad P S \quad P B\}
$$

where the membership function for the control input variables are shown in Figure 9.

Figure 8 Fuzzy logic controller input/output (see online version for colours)

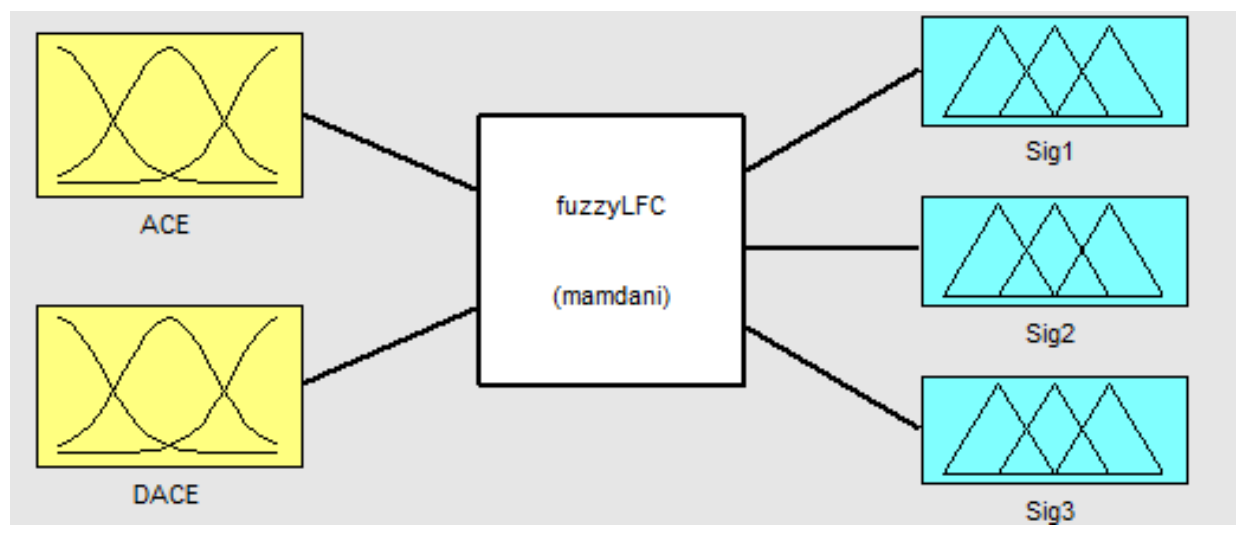


Figure 9 Membership function for the control input variables (see online version for colours)

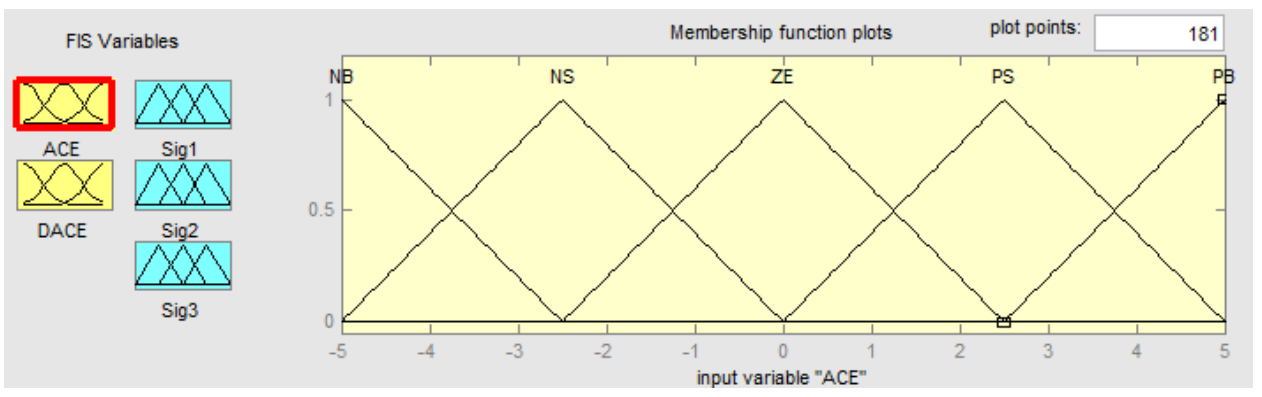

A label set corresponding to linguistic variables of the output control signals is as follows:

$$
\operatorname{Lo}(\operatorname{Sig} 1, \operatorname{Sig} 2, \operatorname{Sig} 3)=\{Z E \quad P S \quad P M \quad P B\}
$$

where the membership function for the control output variables are as shown in Figure 10.

Figure 10 Membership function for the control output variables (see online version for colours)

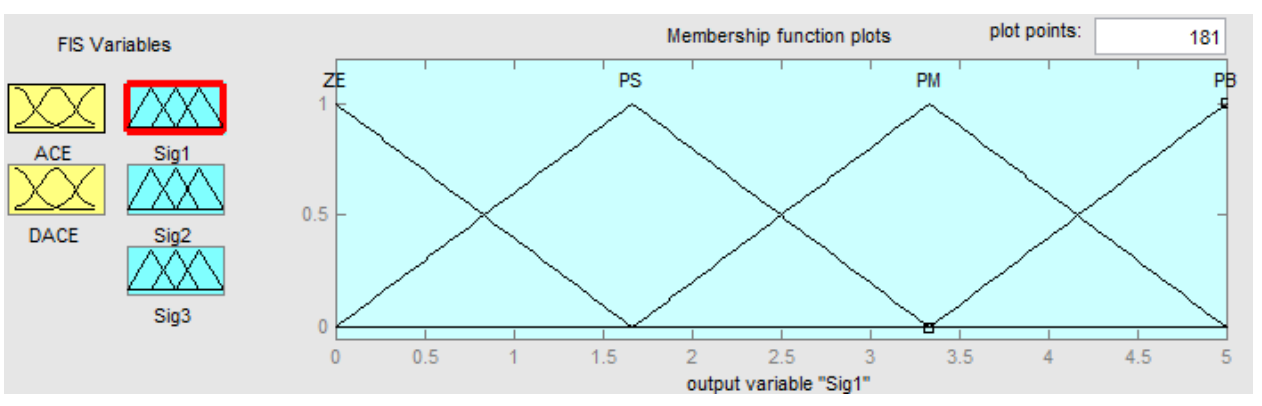

The control rules are built from the statement: if input $a$ and input $b$ then output $c$, and Table 1 resume the control rules used in this paper. The two input signals $(A C E, d A C E)$ are converted to fuzzy numbers first in fuzzifier using five membership functions $\{N B \quad N S \quad Z E \quad P S \quad P B\}$. In this paper the Triangular membership functions was used. Then they are used in the rule table shown in Table 1 to determine the fuzzy number of the compensated output signals.

Table 1 Control rules

\begin{tabular}{llllll}
\hline \multirow{2}{*}{$A C E$} & \multicolumn{5}{c}{$d A C E$} \\
\cline { 2 - 6 } & $N B$ & $N S$ & $Z E$ & $P S$ & $P B$ \\
\hline NB & PB & PB & PB & PB & PS \\
NS & PB & PM & PM & PB & PB \\
ZE & PB & PM & ZE & PB & PB \\
PS & PB & PM & PM & PM & PB \\
PB & PS & PB & PM & PM & PB \\
\hline
\end{tabular}


Figure 11 PSO algorithm

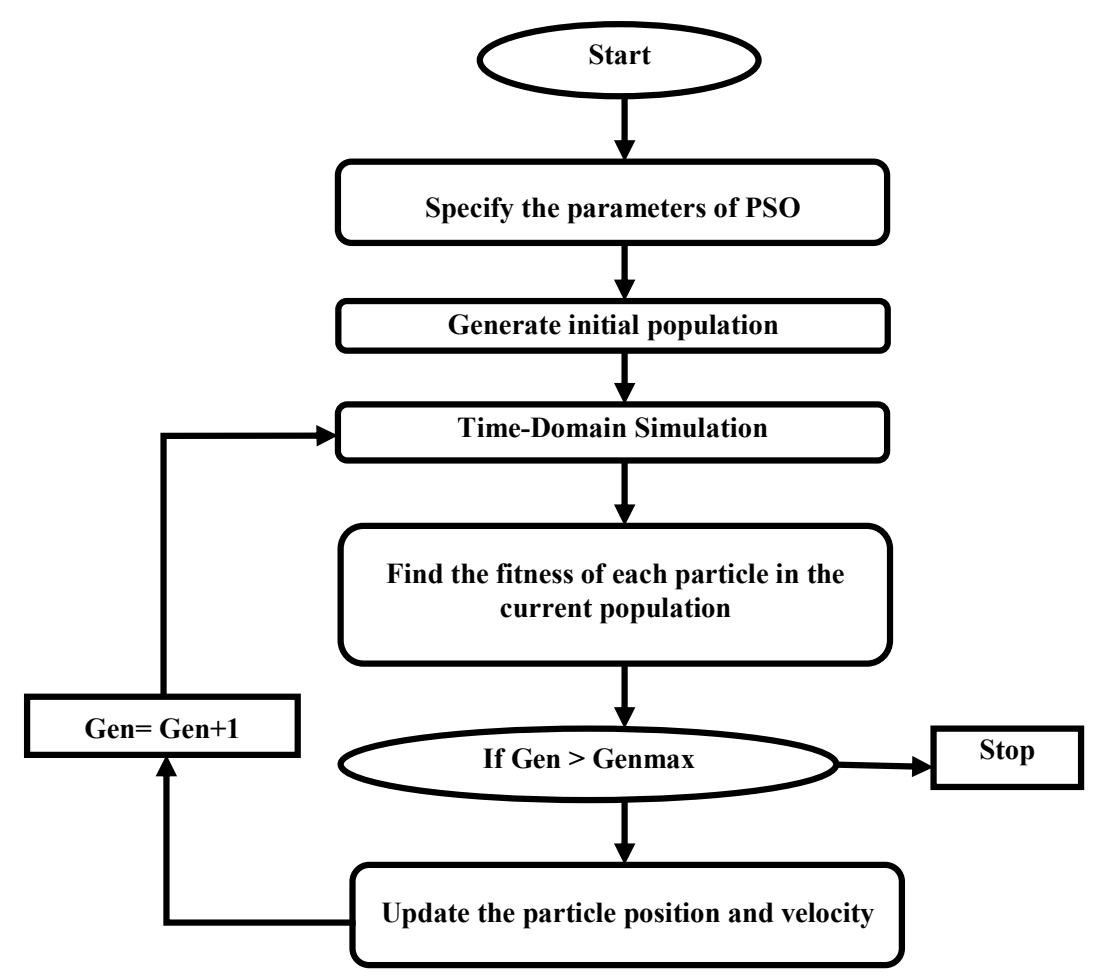

\subsection{PSO algorithm}

The PSO is a heuristic optimisation method based on swarm intelligence. It comes from research on the bird and fish flock movement behaviour. PSO is a population-based optimisation method developed in 1995 by Dr. Kennedy and Dr. Eberhart (Kennedy, 1995). It has become one of the most popular techniques applied in various optimisation problems due to its easiness and capability to find near optimal solutions. It belongs to the class of direct search methods that can be used to find a solution to an optimisation problem in a search space. In the PSO method, a swarm consists of a set of individuals, with each individual specified by position and velocity vectors $(x i(t)$, vi(t)) at each time or iteration. Each individual is named as a 'particle' and the position of every particle represents a potential solution to the under study optimisation problem. The basic algorithm of PSO shown in Figure 11 can be described by these seven steps (Sudha et al., 2010; Kouba et al., 2015e):

1 create a population of agents (called particles) uniformly distributed over $X$

2 evaluate each particle's position according to the objective function

3 if a particle's current position is better than its previous best position, update it

4 determine the best particle (the particle's previous best positions)

5 update particles velocities according to: 


$$
V_{i}^{t+1}=V_{i}^{t}+C_{1} \operatorname{rand}_{1}\left(\text { Pbest }-X_{i}^{t}\right)+C_{2} \operatorname{rand}_{2}\left(\text { gbest }-X_{i}^{t}\right)
$$

6 move particles to their new positions according to:

$$
X_{i}^{t+1}=X_{i}^{t}+V_{i}^{t+1}
$$

7 go to step 2 until stopping criteria are satisfied.

\subsection{Objective function}

The global objective function of the LFC problem aims to minimise the fitness function given in equation (20). The problem constraints are the PID controller parameters and the scaling factors of fuzzy logic controller bounds. Performance criteria usually considered in the control design is the integral of time multiplied absolute error (ITAE). ITAE criterion reduces the settling time with a reduced peak overshoot.

$$
I T A E=\int_{0}^{t s i m} t \cdot\left(\left|\Delta f_{1}\right|+\left|\Delta f_{2}\right|+\left|\Delta f_{3}\right|+\mid \Delta \text { Ptie }_{12}|+| \Delta \text { Ptie }_{23}|+| \Delta \text { Ptie }_{31} \mid\right) \cdot d t
$$

Subject to:

$$
\left\{\begin{array}{c}
K_{p \text { min }} \leq K_{p} \leq K_{p \max } \\
K_{i \text { min }} \leq K_{i} \leq K_{i \text { max }} \\
K_{d \text { min }} \leq K_{d} \leq K_{d \text { max }}
\end{array}\right\}\left\{\begin{array}{l}
K_{\mathrm{e} \text { min }} \leq K_{e} \leq K_{\mathrm{e} \text { max }} \\
K_{\mathrm{ec} \text { min }} \leq K_{e c} \leq K_{\mathrm{ec} \max }
\end{array}\right\}
$$

In the above equations, $\Delta f_{1}, \Delta f_{2}$ and $\Delta f_{3}$ are the system frequency deviations; $\Delta P_{\text {tie } 12}$, $\Delta P_{\text {tie23 }}$ and $\Delta P_{\text {tie31 }}$ are the incremental changes in the tie-lines; tsim is the time range of simulation.

\section{Simulation results}

In this work various classical and metaheuristic optimisation algorithms have been applied to design an effective LFC strategy for solving frequency regulation problem. The obtained results have been compared in view of settling time and max deviation. To show the efficiency of the used optimisation algorithms 'IP, GA and PSO' the same objective function was evaluated, which is the ITAE. The investigated techniques have been tested on the same test system. The main task was to find the best parameters of the combined fuzzy-PID controller including the scaling factors of fuzzy logic and the PID controller gains for minimisation system fluctuation during disturbances within a limited computational time.

Noted that, the choice of the PSO algorithm to optimise the combined fuzzy-PID controller gains was based on four major criteria, which are:

1 system solution quality including frequency and tie-line power flow

2 the max system deviation (peak undershoot and peak overshoot)

3 settling time

4 the time needed to reach the best optimum. 
Focusing basically on the ability of the algorithm to find the best solution and satisfy the cited criteria above, the simulation was carried out in two steps. In the first step the simulation was performed using PID controller only based classical and metaheuristic techniques to choose the best algorithm, after that, the obtained results have been compared with the fuzzy logic controller and then in the second step the chosen optimisation algorithm (in this case PSO) was used to design an optimal combined fuzzyPID controller.

Two scenarios have been analysed to show the potential of the suggested control strategy in monitoring a multi-area power system. The simulation results of the proposed intelligent LFC loop-based optimal fuzzy-PID controller using PSO strategy were presented in this section. Firstly, the same controller was proved in each area and the three-area 9 unit model was simulated for a multi step load disturbances $(0.1 \mathrm{pu})$ in area$1,(0.05 \mathrm{pu})$ in area- 2 , and $(0.05 \mathrm{pu})$ in area-3. Then, the simulation was extended with different controllers in each area. For comparison purpose, the dynamics responses of the proposed methodology over load change were analysed with various control strategy. The frequency restoration assessment was mainly based on two major keys, which are the settling time and the max deviation (peak undershoot and peak overshoot).

Table 2 Controller parameters

\begin{tabular}{lccccc}
\hline & $K p$ & $K i$ & $K d$ & $K e$ & $K e c$ \\
\hline Ziegler-Nichols & 0.1341 & 0.6 & 0.15 & - & - \\
IP & 0.4832 & 6.2725 & 0.9711 & - & - \\
GA & 0.4343 & 2.2732 & 0.9536 & - & - \\
PSO & 0.9702 & 5.6166 & 1.7268 & - & - \\
Fuzzy-PID & 3 & 1.665 & 3.2833 & 1 & 1 \\
Proposed optimal fuzzy-PID-PSO & 2.4496 & 10.2390 & 1.9691 & 0.3667 & 0.5241 \\
\hline
\end{tabular}

Figure 12 Frequency fluctuation in Area-1 (see online version for colours)

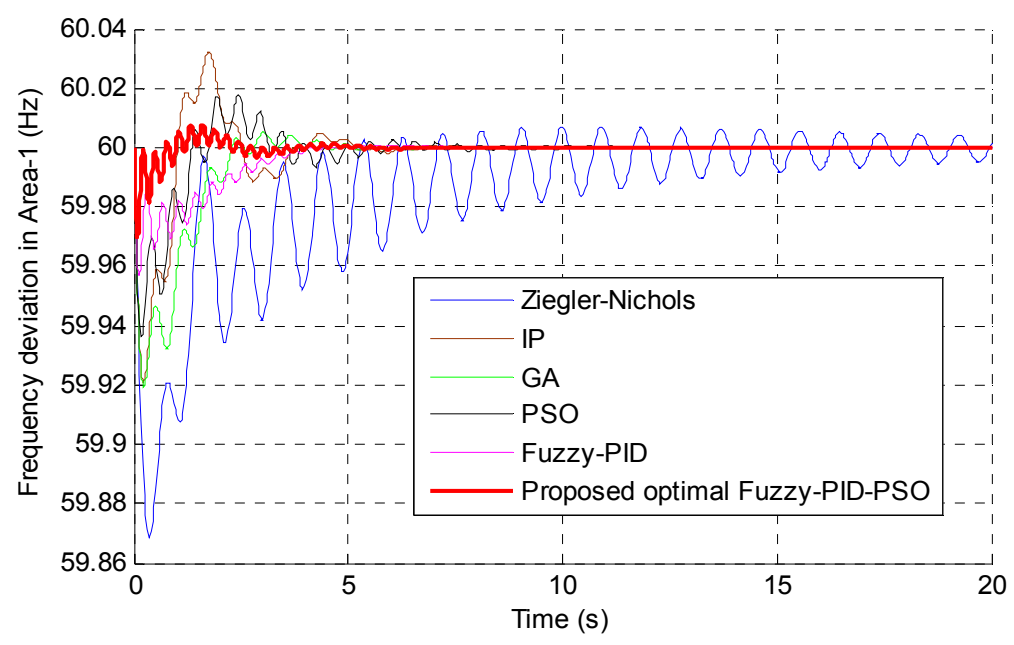


Figure 13 Frequency fluctuation in Area-2 (see online version for colours)

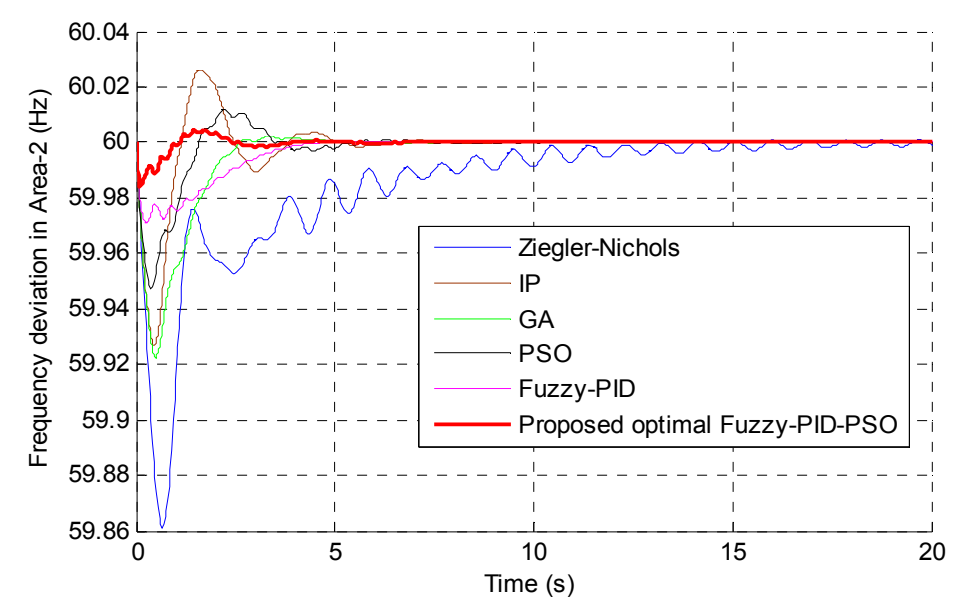

Figure 14 Frequency fluctuation in Area-3 (see online version for colours)

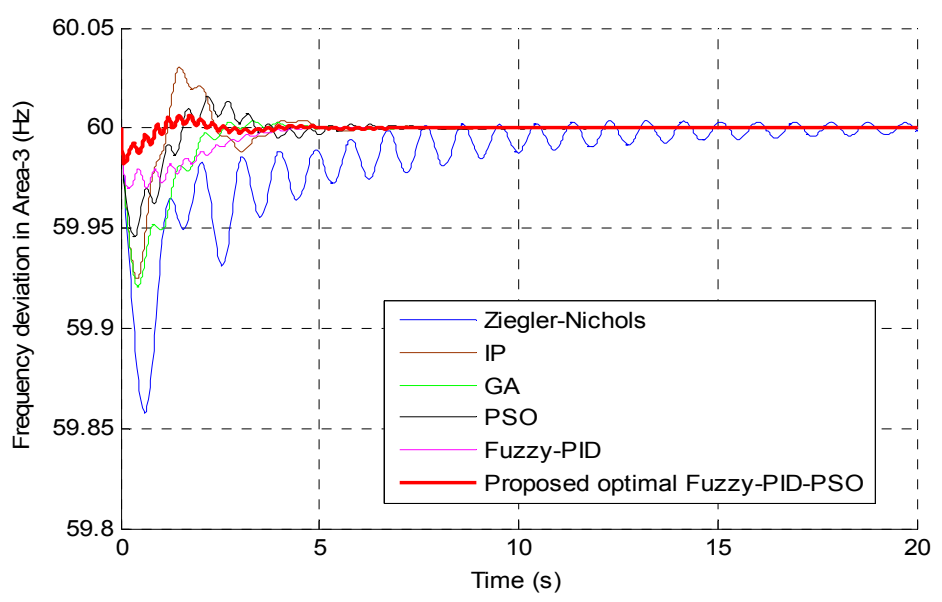

Figure 15 Tie-line ${ }_{12}$ fluctuation between Area-1 and Area-2 (see online version for colours)

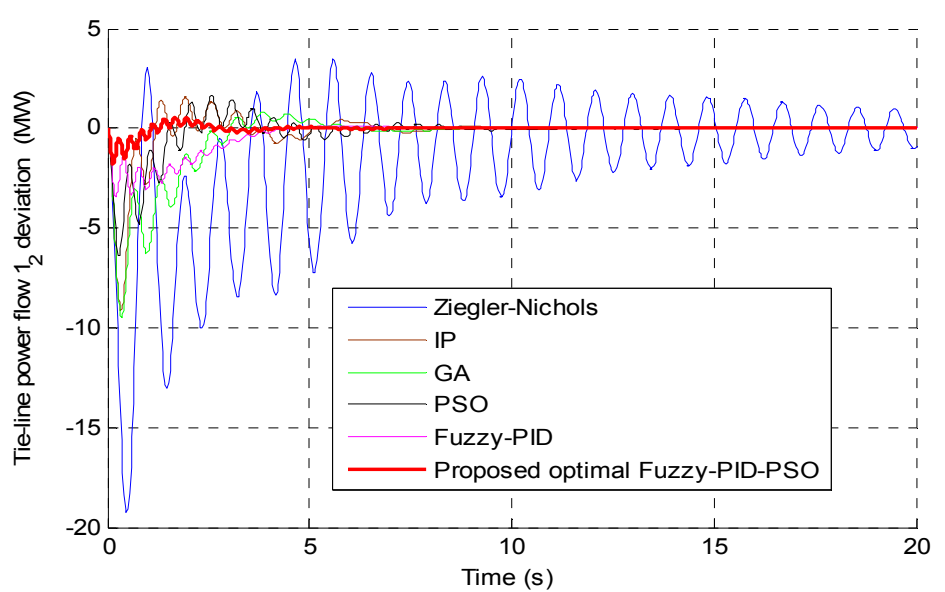


Figure 16 Tie-line ${ }_{13}$ fluctuation between Area-1 and Area-3 (see online version for colours)

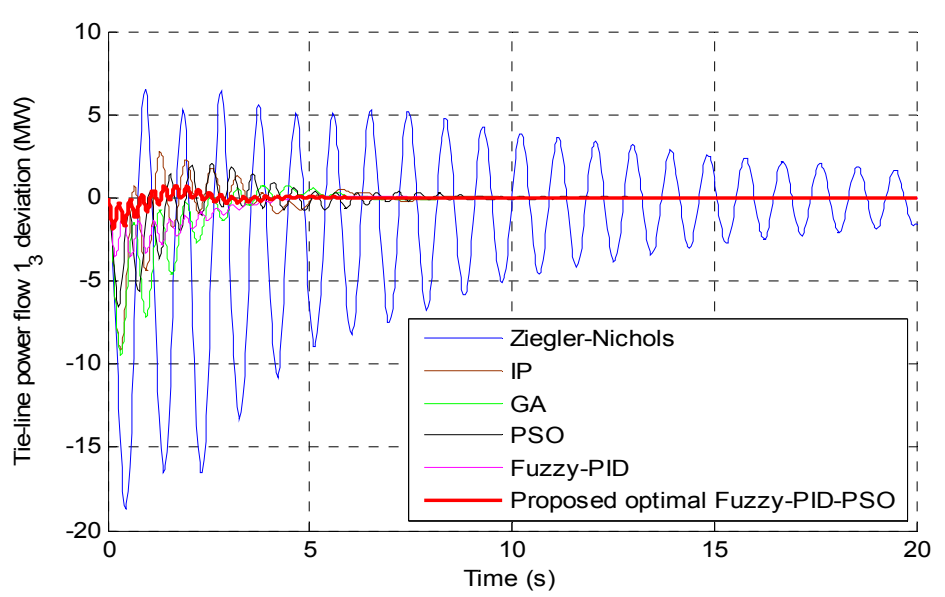

Figure 17 Tie-line ${ }_{23}$ fluctuation between Area-2 and Area-3 (see online version for colours)

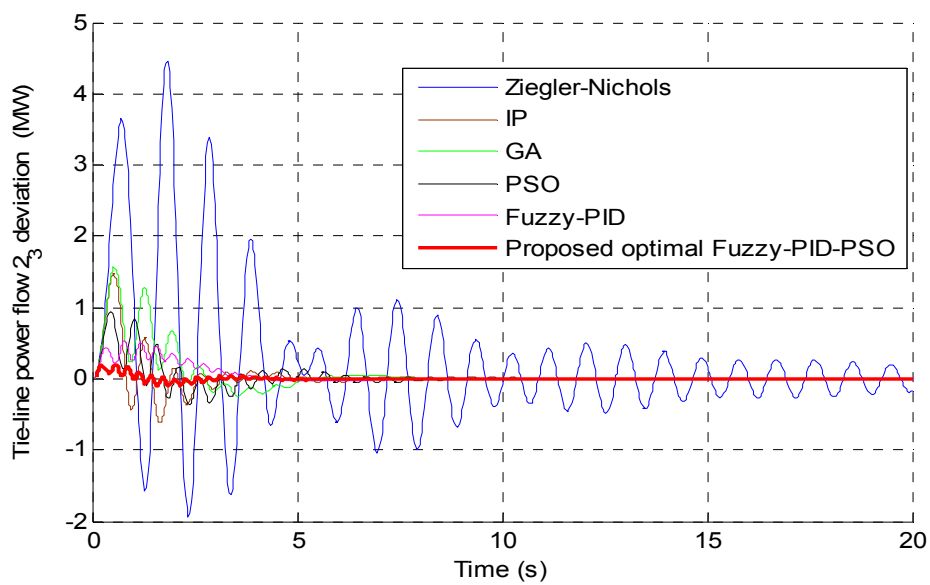

\subsection{Case 1: with same controller parameters in all areas}

In the first part, the test system was faced to multi-step load disturbance, and the same LFC controller was used to regulate the three interconnected area. Each Thermal unit was equipped with primary frequency controller through the governor-turbine system and a secondary restoration frequency loop via the LFC loop. The PSO algorithm was applied to optimise the controller gains and the results are compared with classical Ziegler-Nichols method, interior point (IP) method, GA, PSO and fuzzy logic controller (Kouba et al., 2015d). The controller parameters are sited in Table 2 and the system results are shown in Figures 12 to 17.

Firstly, the empirically Ziegler-Nichols method was used to find the PID controller gains and then 'IP, GA and PSO' algorithms were employed to optimise the PID controller parameters only using the same objective function 'ITAE'. For comparison purpose, the same generations, population size, search dimension size, lower bound and upper bound of the optimised parameters have been used during the optimisation process 
for all used algorithms. The applied IP, GA and PSO algorithms were compared in terms of quality of the obtained solution, the settling time and maximum fluctuation and in view of algorithm convergence speed. It is noticed that during simulation both IP and GA takes more time to find the optimum, where PSO can converge rapidly within less computational time. In addition, compared with the obtained results from IP and GA, PSO gives the best responses with minimum deviation and short settling time. Following the results from simulation of the first step, it is evident that PSO gives good results and converges faster within an acceptable execution time. For this reason, PSO algorithm was selected to design an optimised fuzzy-PID controller.

It is clear from the presented results, that the proposed optimal fuzzy-PID controller-based PSO algorithm gives good responses and their implementation presents encouraging results to face load disturbances. The system frequency and the tie-line power flow are suppressed most effectively. Using classical PID controller the settling time was much bigger than the case with optimal PID-based IP, GA or PSO. In addition, by comparing the obtained results from the optimised PID controller, the difference between IP, GA and PSO is well highlighted. The minimum value of frequency and tieline power flow deviations are much more improved by proposed PSO method than by applying the IP or GA algorithm. Also the computational time of PSO is lower than IP and GA algorithm. The results show that PSO is more robust in global searching ability and computational efficiency.

On the other hand, using the parallel combination between fuzzy logic controller and PID controller, the time of suppressing the fluctuation is very short compared with the time given by the single PID and fuzzy controllers. Moreover, applying the proposed methodology which involves the combined fuzzy-PID controller optimised by PSO ensures the frequency stability and reduces the system fluctuations with a minimal settling time.

Using the classical Ziegler-Nichols (Z-N) method, the maximum steady-state frequency deviation was $0.1291 \mathrm{~Hz}$ in area-1, $0.1379 \mathrm{~Hz}$ in area-2 and $0.1403 \mathrm{~Hz}$ in area3 , where the settling time was $29.87 \mathrm{sec}$ in area-1, $21.3 \mathrm{sec}$ in area-2 and 30 in area-3. Further, it can be observed that using IP, GA, PSO and fuzzy controller, a significant enhancement was reached in the transient responses, where both max deviation and settling time were reduced compared with the classical Z-N. On the other hand, using the suggested optimal fuzzy-PID-based PSO, a better results are achieved with less fluctuation and short settling time, the frequency deviation was reduced from 0.1291 to $0.03 \mathrm{~Hz}$ in area-1, and from 0.1397 to $0.02 \mathrm{~Hz}$ in area-2, and from 0.1403 to $0.018 \mathrm{~Hz}$ in area-3, where the settling time was reduced from 29.87 to $3.81 \mathrm{sec}$ in area-1, and from 21.3 to $3.77 \mathrm{sec}$ in area-2 and from 30 to $3.72 \mathrm{sec}$ in area-3. In addition, the tie-lines power flow fluctuations are reduced from 19.05 to $1.518 \mathrm{MW}$ in the tie-line12 and from 4.462 to $0.1766 \mathrm{MW}$ in the tie-line23 and from 18.44 to $1.756 \mathrm{MW}$ in the tie-line13, where the settling time was reduced for the same tie-lines from 30 to $5.21 \mathrm{sec}, 5.45 \mathrm{sec}$ and to $6.3 \mathrm{sec}$ respectively. The results are compared and the potential of the proposed control strategy was proven.

\subsection{Case 2: with different controller parameters}

In order to verify the effectiveness of proposed control strategy, different optimised fuzzy-PID controllers were performed in each control area. The frequency system was analysed and the results are discussed in cases of same and different controller 
parameters. Additionally, in this problem of finding effective fuzzy-PID controller parameters, lower bound (LB) and upper bound (UB) of controller parameters are fixed based on previous simulation, which help to find the best solution within a given time limit. Moreover, the generation's number in the PSO was also limited to avoid continuation of calculation and to prevent waste of time. The frequency fluctuation and the tie-lines power changes response are shown in Figures.18-23 respectively and the controller parameters of each area are sited in Table 3. The simulation parameters that are used in this work are cited in Table 4.

Figure 18 Frequency fluctuation in Area-1 (see online version for colours)

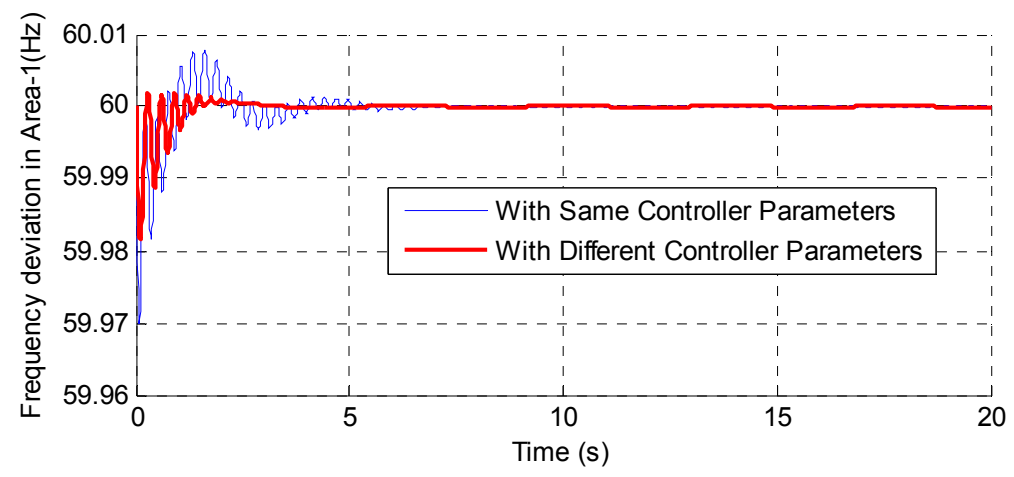

Figure 19 Frequency fluctuation in Area-2 (see online version for colours)

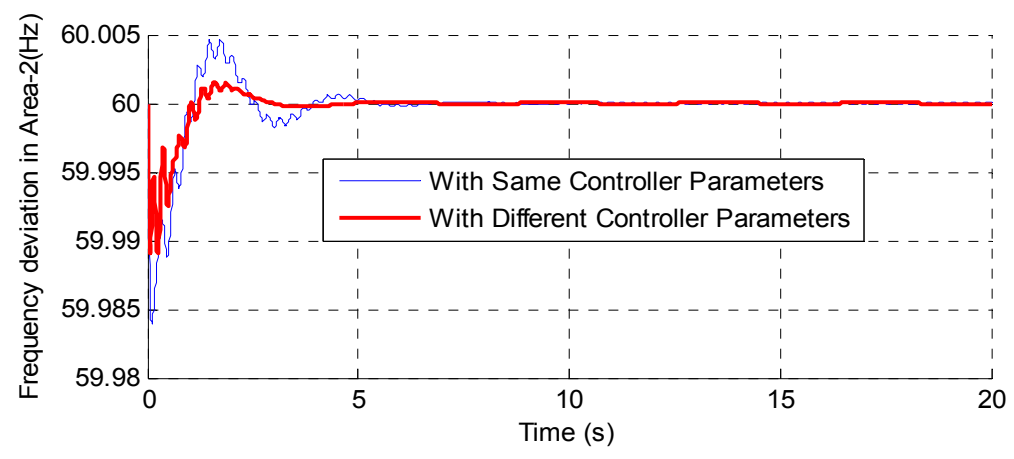

Figure 20 Frequency fluctuation in Area-3 (see online version for colours)

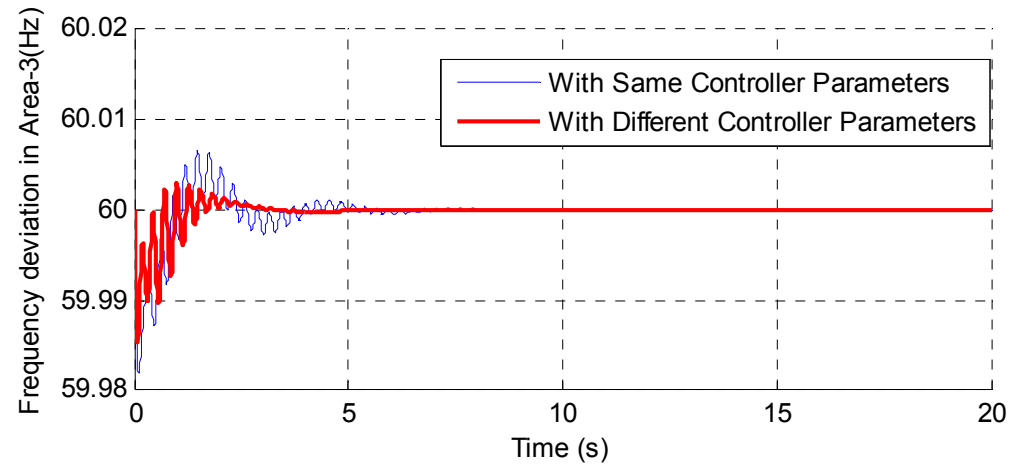


Figure 21 Tie-line 12 fluctuation between Area-1 and Area-2 (see online version for colours)

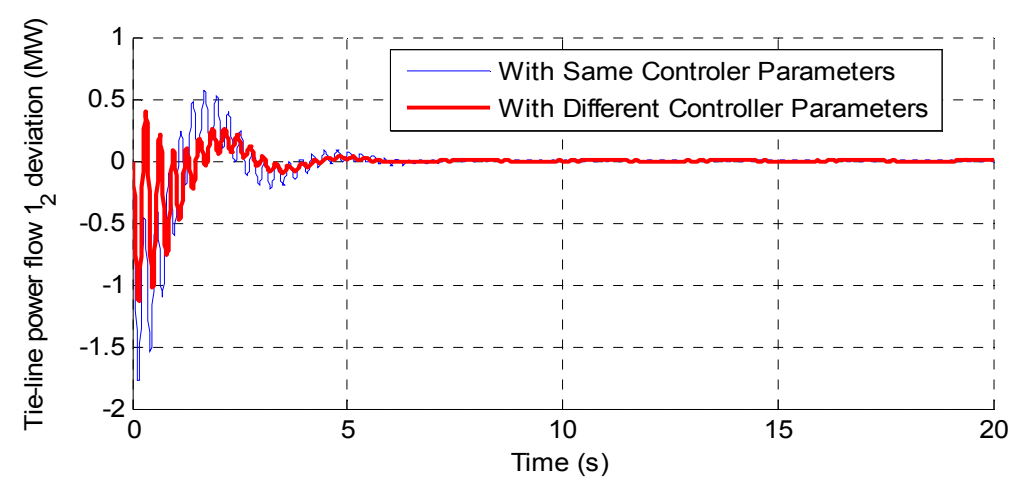

Figure 22 Tie-line 13 fluctuation between Area-1 and Area-3 (see online version for colours)

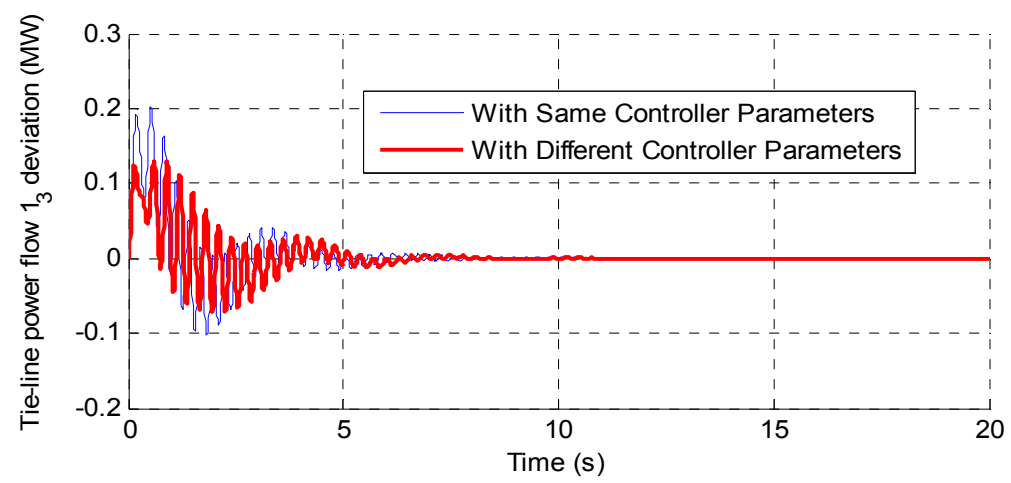

Figure 23 Tie-line 23 fluctuation between Area-2 and Area-3 (see online version for colours)

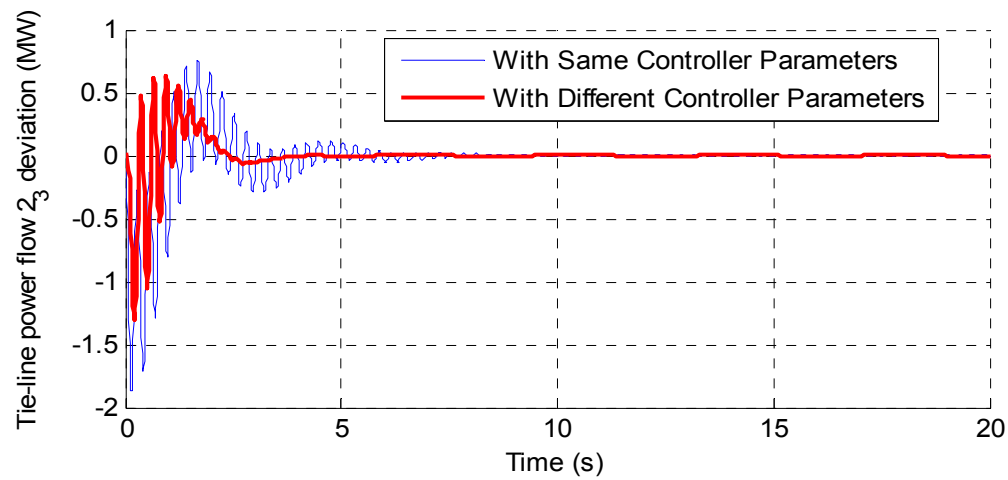


Table 3 Fuzzy-PID controller parameters

\begin{tabular}{lccccc}
\hline & $K p$ & $K i$ & $K d$ & $K e$ & $K e c$ \\
\hline Area-1 & 2.9550 & 9.1623 & 1.4165 & 0.6544 & 0.5783 \\
Area-2 & 0.3533 & 10.6996 & 3.4076 & 0.9605 & 0.8359 \\
Area-3 & 5.9212 & 8.8469 & 2.3741 & 0.6884 & 0.8735 \\
\hline
\end{tabular}

Table 4 Simulation parameters

\begin{tabular}{lccccc}
\hline & $K p$ & $K i$ & $K d$ & $K e$ & $K e c$ \\
\hline Lower bound (LB) & 0 & 0 & 0 & 0 & 0 \\
Upper bound (UB) & 30 & 30 & 30 & 1 & 1 \\
\hline$I P$, GA, PSO & Max generation & Population size & Search dimension \\
\hline Only PID & 100 & 20 & \multicolumn{2}{c}{3} \\
Same fuzzy-PID & 100 & 30 & \multicolumn{2}{c}{15} \\
Different fuzzy-PID & 200 & 50 & & \\
\hline
\end{tabular}

A significant enhancement was reached when different controllers are performed in each control area. Based on the presented figures, it can be observed that the intelligent frequency restoration loop gives a good improvement in view of frequency settling time and peak overshoot. The results are satisfying and the proposed control strategy presents a very powerful tool to monitor and manage a multi-area power system. Moreover, it can be said that the suggested methodology was the right solution to ensure frequency stability.

\section{Conclusions}

This paper has presented the design of an intelligent frequency restoration LFC loop using a new optimised fuzzy-PID controller based on PSO algorithm. The proposed control strategy was applied to minimise frequency deviation and enhance power system stability during disturbances. The PSO technique was employed to optimise the scaling factors of fuzzy logic and the PID controller gains in the three-area 9-unit interconnected power system. The validity of the proposed approach was demonstrated by comparing the obtained results to other published approaches available in literature such as Ziegler-Nichols (Z-N) method, interior point (IP) method, GA, PSO and to the fuzzy logic controller. A comparative performance in view of max deviation and settling time was performed.

It can be observed from the obtained results that the performance of the optimised fuzzy-PID-based PSO is better than other applied controller against to the load perturbation at any area, and it has been shown that the proposed controller seems to be the most effective and robust as the frequency and the tie-line power flow deviations are relatively small compared to the Z-N, IP, GA, PSO and fuzzy logic approaches. Also, from the qualitative and quantitative comparison of the results it is clear that the optimised fuzzy-PID-based PSO provides significant improvement in system performance. From the simulation results of this work it is revealed that, the proposed control methodology presents a very powerful strategy to solve LFC problem and may 
become a very promising tool for solving more complex power system optimisation problems. Further, application of the proposed strategy on large interconnected multi-area power system with nonlinearity such as generation rate constraints (GDB), time delay and governor dead band (GRC) might be suggested for future work.

\section{References}

Astrom, K.J. and Hagglund, T. (2001) 'The future of PID control', CEP, Vol. 9, No. 11, pp.1163-1175, Elsevier.

Bevrani, H. (2009) Robust Power System Frequency Control, Springer, New York.

Bevrani, H. and Daneshmand, P.R. (2012) 'Fuzzy logic-based load-frequency control concerning high penetration of wind turbines', IEEE Systems Journal, Vol. 6, No. 1, pp.173-180.

Chandra Saikia, L. and Kant Sahu, S. (2013) 'Automatic generation control of a combined cycle gas turbine plant with classical controllers using Firefly Algorithm', Electrical Power and Energy Systems, Vol. 53, pp.27-33.

Chavda, N.K. and Prabhakaran, P. (2015) 'Analysis of thermal system network of an ammonia plant using genetic algorithms - Part I: synthesis and optimisation', Int. J. of Process Systems Engineering, Vol. 2, No. 1, pp.36-69.

Daliri, Z.S., Shamshirband, S. and Besheli, M.A. (2011) 'Railway security through the use of wireless sensor networks based on fuzzy logic', International Journal of the Physical Sciences, Vol. 6, No. 3, pp.448-458.

Kennedy, J. (1995) 'Particle swarm optimization', IEEE, International Conference on Neural Networks, Vol. IV, pp.1942-1948.

Kerdphol, T., Qudaih, Y.S., Basri, K.H. and Mitani, Y. (2015) 'Robust hydro-thermal power system controller considering energy capacitor system and wind power source', Int. J. of Process Systems Engineering, Vol. 3, Nos. 1/2/3, pp.90-109.

Kirby, B.J., Dyer, J. and Martinez, C. et al. (2001) Frequency Control Concerns in the North American Electric Power System [online] http://www.ornl.gov/ webworks/cppr/y2001/rpt/116362.pdf (accessed 2016).

Kouba, N.E.Y., Menaa, M., Hasni, M. and Boudour, M. (2014a) 'Application of artificial neural networks to load frequency control in multi-area power system', Proceedings of the $3 \mathrm{rd}$ International Conference on Information Processing and Electrical Engineering, pp.357-362.

Kouba, N.E.Y., Menaa, M., Hasni, M., Boussahoua, B. and Boudour, M. (2014b) 'Optimal load frequency control based on hybrid bacterial foraging and particle swarm optimization', IEEE, 11th International Multi-Conference on Systems, Signals \& Devices, (SSD-PES), pp.1-6.

Kouba, N.E.Y., Menaa, M., Hasni, M., Boussahoua, B. and Boudour, M. (2014c) 'Optimal load frequency control in interconnected power system using PID controller based on particle swarm optimization', IEEE International Conference on Electrical Sciences and Technology in Maghreb CISTEM, pp.1-8, Tunis, Tunisia.

Kouba, N.E.Y., Menaa, M., Hasni, M. and Boudour, M. (2015a) 'A novel robust automatic generation control in interconnected multi-area power system based on bat inspired algorithm', IEEE, 3rd International Conference on Control, Engineering \& Information Technology, CEIT, pp.1-6.

Kouba, N.E.Y., Menaa, M., Hasni, M. and Boudour, M. (2015b) 'Design of robust secondary frequency controller based on gravitational search algorithm', International Conference on Automatic control, Telecommunication and Signals (ICATS), pp.1-6.

Kouba, N.E.Y., Menaa, M., Hasni, M. and Boudour, M. (2015c) 'Frequency stability and control based intelligent PI controller: a case study of the South-Western Mediterranean interconnected power system', CIGRE, Algerian Large Electrical Network Conference, (CAGRE), pp.403-410. 
Kouba, N.E.Y., Menaa, M., Hasni, M. and Boudour, M. (2015d) 'Load frequency control in multi-area power system based on fuzzy logic-PID controller', IEEE, International Conference on Smart Energy Grid Engineering SEGE, pp.1-6, Oshawa, Canada.

Kouba, N.E.Y., Menaa, M., Hasni, M. and Boudour, M. (2015e) 'Optimal control of frequency and voltage variations using PID controller based on particle swarm optimization', IEEE, 4th International Conference on Systems and Control ICSC'15, pp.424-429.

Kouba, N.E.Y., Menaa, M., Hasni, M. and Boudour, M. (2015f) 'Optimal load frequency control based on artificial bee colony optimization applied to single, two and multi-area interconnected power systems', IEEE, 3rd International Conference on Control, Engineering \& Information Technology, CEIT'15, pp.1-6.

Krokavec, D. and Filasova, A. (2012) 'Optimal fuzzy control for a class of nonlinear systems', Mathematical Problems in Engineering, Vol. 2012, Article ID 481942, pp.1-29.

Kundur, P. (1994) Power System Stability and Control, McGraw-Hill, New York.

Mallesham, G. and Rajani, A. (2006) 'Automatic tuning of PID controller using fuzzy logic', 8th International Conference on Development and Application Systems, pp.120-127.

Modi, N., Khare, M. and Chaturvedi, K. (2013) 'Performance analysis of load frequency control in single area power system using GA and PSO based PID controller', International Journal of Electrical, Electronics and Computer Engineering, Vol. 2, No. 1, pp.108-114.

Murty, P.S.R. (2008) Operation and Control in Power Systems, Ch. 6-7, BS Publications, Hyderabad.

Nageswara, R. and Reddy, P.R.K. (2011) 'PSO based tuning of PID controller for a load frequency control in two area power system', IJERA, Vol. 1, No. 3, pp.1499-1505.

Natsheh, E. and Buragga, K.A. (2010) 'Comparison between conventional and fuzzy logic PID controllers for controlling DC motors', International Journal of Computer Science, Vol. 7, No. 5, pp.128-134.

Panda, R.C. and Tade, M.O. (2011) 'Modified Smith predictor with PID structure for control of multivariable processes', Int. J. of Process Systems Engineering, Vol. 1, No. 2, pp.197-214.

Panda, S. and Kumar Yegireddy, N. (2013) 'Automatic generation control of multi-area power system using multi-objective non-dominated sorting genetic algorithm-II', Electrical Power and Energy Systems, Vol. 53, pp.54-63.

Panda, S., Mohanty, B. and Hota, P.K. (2013) 'Hybrid BFOA-PSO algorithm for automatic generation control of linear and nonlinear interconnected power systems', Applies Soft Computing, Vol. 13, No. 12, pp.4418-4730.

Rahmani, M. and Sadati, N. (2013) 'Two-level optimal load-frequency control for multi-area power systems', Electrical Power and Energy Systems, Vol. 53, pp.540-547.

Ram, P. and Jha, A.N. (2010) 'Automatic generation control of interconnected hydro-thermal system in deregulated environment considering generation rate constraints', International Conference on Industrial Electronics, Control and Robotics, pp.148-159.

Rerkpreedapong, D., Hasanovic, A. and Feliachi, A. (2003) 'Robust load frequency control using genetic algorithms and linear matrix inequalities', IEEE Transactions on Power Systems, Vol. 18, No. 2, pp.855-861.

Salim Ali, E. and Abd-Elazim, S.M. (2010) 'Optimal PID tuning for load frequency control using bacteria foraging optimization algorithm', Proceedings of the 14th International Middle East Power Systems Conference (MEPCON'10), pp.410-415.

Shankar, R., Chatterjee, K. and Chatterjee, T.K. (2012) 'Genetic algorithm based controller for load-frequency control of interconnected systems', 1st Int'l. Conf. on Recent Advances in Information Technology, pp.392-397, IEEE.

Shirvani, M., Abdollahi, M., Memaripour, A. and Behzadipour, E. (2012) 'Multi-area load frequency control using IP controller tuned by Tabu search', Przeglad Elektrotechniczny (Electrical Review), Vol. 88, No. 8, pp.244-248. 
Sudha, K.R., Vakula, V.S. and Shanthi, R.V. (2010) 'PSO based design of robust controller for two area load frequency control with nonlinearities', International Journal of Engineering Science and Technology, Vol. 2, No. 5, pp.1311-1324.

Tang, K.S., Man, K.F. and Chen, G. (2000) 'Solar plant control using genetic fuzzy PID controller', 26th Annual Conference of the IEEE Industrial Electronics Society, Vol. 3, pp.1686-1691.

Verma, R., Pal, S. and Sathans (2013) 'Intelligent automatic generation control of two-area hydrothermal power system using ANN and Fuzzy logic', IEEE, International Conference on Communication Systems and Network Technologies, pp.552-556.

Volosencu, C. (2012) 'Tuning fuzzy PID controllers', in Panda, R.C. (Ed.): Introduction to PID Controllers - Theory, Tuning and Application to Frontier Areas, ISBN: 978-953-307-927-1, InTech [online] http://www.intechopen.com/books/introduction-to-pid-controllers-theorytuning-and-application-tofrontier- areas/tuning-fuzzy-pid-controllers (accessed 2016), DOI: $10.5772 / 2422$.

Wang, C. and McCalley, J.D. (2013) 'Impact of wind power on control performance standards', Electrical Power and Energy Systems, Vol. 47, pp.225-234.

Wood, J. and Wollenberg, B.F. (1966) Power Generation Operation and Control, 2nd ed., pp.328-362, John Wiley \& Sons, New York.

$\mathrm{Wu}, \mathrm{L}$. and Yang, J.M. (2013) 'Load frequency control of area power system with multi-source power generation units based on differential games tracking control', Power and Energy Engineering Conference (APPEEC), IEEE PES Asia-Pacific, pp.1-6.

Yousef, H.A., Al-Kharusi, K., Albadi, M.H. and Hosseinzadeh, N. (2014) 'Load frequency control of a multi-area power system: an adaptive fuzzy logic approach', IEEE Transactions on Power Systems, Vol. 29, No. 4, pp.1822-1830.

Zadeh, L.A. (1965) 'Fuzzy sets', Inform. Contr., Vol. 8, No. 3, pp.338-353.

Zamani, A.A., Bijami, E., Sheikholeslam, F. and Jafrasteh, B. (2014) 'Optimal fuzzy load frequency controller with simultaneous auto-tuned membership functions and fuzzy control rules', Turkish Journal of Electrical Engineering \& Computer Sciences, Vol. 22, No. 1, pp.66-86.

Ziegler, J.G. and Nichols, N.B. (1942) 'Optimum settings for automatic controllers', Trans. ASME, Vol. 64, No. 11, pp.759-768. 


\section{Appendix}

The matrices $A, B$ and $C$ are given by:

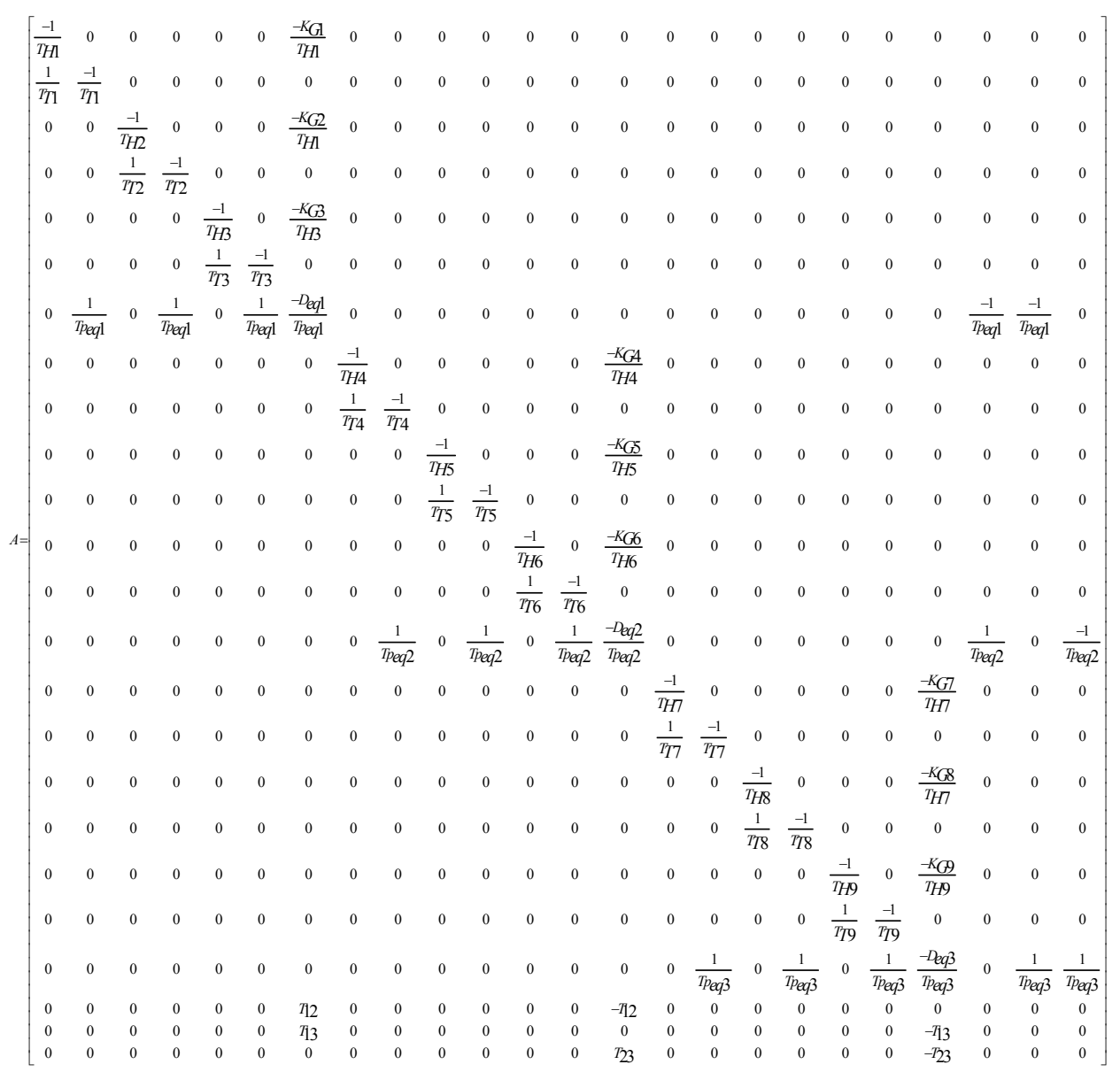

$B=\left[\begin{array}{ccccccccccccccccccccccccc}0 & 0 & 0 & 0 & 0 & 0 & -\frac{1}{M_{e q 1}} & 0 & 0 & 0 & 0 & 0 & 0 & 0 & 0 & 0 & 0 & 0 & 0 & 0 & 0 & 0 & 0 & 0 \\ 0 & 0 & 0 & 0 & 0 & 0 & 0 & 0 & 0 & 0 & 0 & 0 & 0 & -\frac{1}{M_{e q 2}} & 0 & 0 & 0 & 0 & 0 & 0 & 0 & 0 & 0 & 0 \\ 0 & 0 & 0 & 0 & 0 & 0 & 0 & 0 & 0 & 0 & 0 & 0 & 0 & 0 & 0 & 0 & 0 & 0 & 0 & 0 & -\frac{1}{M_{e q 3}} & 0 & 0 & 0 \\ \frac{1}{T_{H 1}} & 0 & \frac{1}{T_{H}} & 0 & \frac{1}{T_{H 3}} & 0 & 0 & 0 & 0 & 0 & 0 & 0 & 0 & 0 & 0 & 0 & 0 & 0 & 0 & 0 & 0 & 0 & 0 & 0 \\ 0 & 0 & 0 & 0 & 0 & 0 & 0 & \frac{1}{T_{H 4}} & 0 & \frac{1}{T_{H 5}} & 0 & \frac{1}{T_{H 6}} & 0 & 0 & 0 & 0 & 0 & 0 & 0 & 0 & 0 & 0 & 0 & 0 \\ 0 & 0 & 0 & 0 & 0 & 0 & 0 & 0 & 0 & 0 & 0 & 0 & 0 & 0 & \frac{1}{T_{H 7}} & 0 & \frac{1}{T_{H}} & 0 & \frac{1}{T_{H} 9} & 0 & 0 & 0 & 0 & 0\end{array}\right]$

$C=\left[\begin{array}{llllllllllllllllllllllll}0 & 0 & 0 & 0 & 0 & 0 & 1 & 0 & 0 & 0 & 0 & 0 & 0 & 0 & 0 & 0 & 0 & 0 & 0 & 0 & 0 & 0 & 0 & 0 \\ 0 & 0 & 0 & 0 & 0 & 0 & 0 & 0 & 0 & 0 & 0 & 0 & 0 & 1 & 0 & 0 & 0 & 0 & 0 & 0 & 0 & 0 & 0 & 0 \\ 0 & 0 & 0 & 0 & 0 & 0 & 0 & 0 & 0 & 0 & 0 & 0 & 0 & 0 & 0 & 0 & 0 & 0 & 0 & 0 & 1 & 0 & 0 & 0 \\ 0 & 0 & 0 & 0 & 0 & 0 & 0 & 0 & 0 & 0 & 0 & 0 & 0 & 0 & 0 & 0 & 0 & 0 & 0 & 0 & 0 & 1 & 0 & 0 \\ 0 & 0 & 0 & 0 & 0 & 0 & 0 & 0 & 0 & 0 & 0 & 0 & 0 & 0 & 0 & 0 & 0 & 0 & 0 & 0 & 0 & 0 & 1 & 0 \\ 0 & 0 & 0 & 0 & 0 & 0 & 0 & 0 & 0 & 0 & 0 & 0 & 0 & 0 & 0 & 0 & 0 & 0 & 0 & 0 & 0 & 0 & 0 & 1\end{array}\right]$ 